\title{
Socio-ecological discourse in education for the sustainable development of the North regions
}

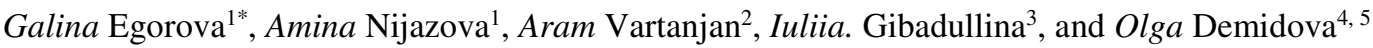 \\ ${ }^{1}$ Surgut State Pedagogical University, 10/2, Street 50 years to AULYCL, Surgut, 62842, Russia \\ ${ }^{2}$ Yugra State University, 16, Chekhov street, Khanty-Mansiysk, 628012, Russia, \\ ${ }^{3}$ FSAEI HE University of Tyumen, 6, Volodarskogo St., Tyumen, 625003, Russia \\ ${ }^{4}$ FSAEI HE National Research Tomsk Polytechnic University, 30, Lenin Avenue, Tomsk, 634050, Russia, \\ ${ }^{5}$ FSAEI HE National Research Tomsk State University, Lenin Avenue 36, Tomsk, 634050, Russia
}

\begin{abstract}
The article deals with a new position of socio-ecological discourse in educating a younger indigenous generation for the sustainable development of the North regions. The concept "socio-ecological competence" has been disclosed as a key personal quality and a specific behavioral model of a younger generation. This concept provides integrity, interaction, interpenetration of cognitive, pragmatic, emotional, problem-solving stimuli, providing successful gap overcommig between knowledge, skills, and abilities of ecological and social focus, their practical application in the society, which a younger indigenous generation follows. The material for studies is a model of developing socio-ecological competence in the younger indigenous generation in the North regions. The theoretico-methodlogical analysis of the model has been grounded on the leading ideas of the sustainable development of the regional communities. Essential principles of socio-ecological discourse in educating a younger indigenous generation for the sustainable development of the North regions, KhMAD - have been disclosed. A model has been developed and tested, as well as content modules, development levels of the socio-ecological competence have been determined, basing on the principle of the socio-ecological discource parameters fulfillment. It has been proved that social and ecological discource is a key direction for the sustainable development of every district.
\end{abstract}

\section{Introduction}

The North of the Tyumen region is considered a strategic real estate; a stand-by and reference edge in Russia. Northern territories in Russia take $66 \%$ of the whole area, where more than ten million citizens live, who contribute to the achievements of the region's economy. Northern territories are a powerful production resource, yielding more than $42 \%$ of GDP[1,2].

With the account of the conceptual focus on a longterm social-economic development (2025 year), Northern territories aim at innovations in society and economy development which creates favorable living conditions for the population of the North [4].

However, with the account of a faster development of the Northern territories, several contradictions appear among:

1. high intensity of the industrial development and rapid reduction of the lands for indigenous people for the traditional household;

2. fast resource development and resource depletion as a traditional support of indigenous people;

3. intensive technologies' development of the Northern territories and unemployment among indigenous people.
Along with the socio-economic contradictions there are problematic socio-ecological issues, which orient the regional community to conceptuality and rationality of their solution.

Let's note negative trends in the development of the indigenous people in the Tyumen North:

- high level of innovations in the society and weak social security of the indigenous people;

- high level of technology and antropocentric nature of the region demands high sociolo-ecological competence of every indiginous citizen.

It should be noted that the key sector of the economy in the region is oil and gas extraction and processing. It is not a secret that the fieldwork is conducted by integrated enterprises (more than 85 names), which requires new methods of recording technogenity, protective measures for social and ecological welfare.

These contradictions and modern conditions necessiate increasing the level of socio-ecological competence and thinking among younger generaion of indigenous people in Northern Territories. This fact is undeniable as the contemporary education of the younger indigenous population suggests separation of a person from traditional life that influences socialization, ethnicity and environmental friendliness of a person. 


\section{Problem statement}

These contradictions conditioned a set of the following problem objectives. What is the subject matter of the social and ecological discourse for the sustainable development of the region? What are the possibilities for socio-ecological education of a younger indigenous population in the North, preparation to the life activity in the regional community of the North? The solution of these issues has a significant contribution into the consistancy of the region's development.

It is important to understand the concept "sustainable development" from several positions. From the point of view of the social discourse, sustainable development in the region is understood as possibility of students' further living in the region, as they are subjects of the education. From the point of view of the ecological discourse it is disclosing and positioning ecological knowledge with the account of the value components in the regional area, which is important for upbringing a younger indigenous generation [10].

For complex study of the objective of the article let's specify the contents of the social and ecological discourses, built into the model of socio-ecological education for indigenous people for the sustainable development and living of the North Regions.

\section{Discription of the subject of the article}

During literature review more than 200 definitions of the concept "sustainable development" have been analyzed. It allowed determining the core of the concept, based on the integrative interaction of sociality, cost effectiveness, environmental friendliness - as characteristic trends of human life and activities [7]. Special mentioning should go to the definition which presents: progressive development and absence of irreversible changes in biosphere, preservation of non-renewable resources, equal possibility for younger indigenous people [8]. The key invariant core focuses on such parameters as: anthropocentricity (survival factor, humanity development) and bio-sphere centricity (preserving biogeosphere as an existancial basis). According to such researchers as K.YA. Kondratiev and K.S. Losev) [9], to achieve sustainable development it is necessary to solve such issues as: relation of the society and nature (socioecological problem); natural depletion as the activity base (eco-economical issue); enhancing the level of living of indigenous people (socio-ecological problem).

Current understanding of the concept "sustainable development" aims at a special self-organization of a younger generation, a society for understanding the importance of the socio-ecological discourse, its efficiency, safety for living [5,11].

Socio-ecological discourse of educating a younger indigenous people has been and is widely discussed [10]. Categorial-conceptual field of the concept "socialecological discourse" has been determined and proved. In our research we talk about the dialectal dependance of the internal structure of the concept "socio-ecological discourse" we study it within the parameters of the dialectal dependance "system - environment- process result". The universal nature of the dialectal dependence has been proved by the fact that it is manifested in all spheres of activity (animate and inanimate nature, cognition, education, including parameters of methodology, content, principles of cognition and education).

Socially-oriented discourse is aimed at preserving and stability of some systems (society and nature), elimination of distructions and conflic situations in the regional comunity. We pay special attention to the parameters of fair welfare division, preserving cultural herritage by the younger generation, developing interconnection between the generations of indigenous people.

The key result of the social discourse is to orient every representative of a young indigenous generation to understanding society and culture as spheres of regional life, their monitoring and increase.

Ecological discourse is aimed at provision and preserving biosphere, nature (its internal and external parameters). Biosphere as a sphere of life and stability includes regional spheres, as dynamic systems, which constantly recover independently and improve (industrial, urban, educational and so on). Herewith, every active environment is ecologized with the account of ecological laws and principles [4].

From this perspective let's note conceptual ideas, created on the principles of ecologization and socialization, which provide methodological grounds for developing main blocks of the model for socioecological education of a younger indigenous generation for the sustainable development of the North region.

Basing on the conceptual ideas (U.V. Bromley, A.P. Gudyma) we stress the integrity of the model for socioecological education including the parameters of the environment as a combination of interactions, which provide the fulfillment of the idea of the sustainable development in the region, combination of the conditions, content, preparing indigenous population to life activity. Socio-ecological educational environment integrates scientific achievements of different spheres, fulfills them in practical activity and gives an opportunity to include content areas of the sustainable development of the region, both into subject areas and practical activity of teachers and students. It is the first conceptual foundation.

The second conceptual foundation is formed by integrating ideas disclosing functionally important aims for socio-ecological content [6]. Conceptual importance of socio-ecological content is based on the invariant and variative part of the whole education within the sustainable development of the region: a) invariative features of socio-ecological content are incorporated into enlarged modules of the subject areas; b) the variative part operates by independent enlarged modules of ecological and social content including ideas of the sustainable development of the region into the system of elective and optional courses. 
The model of socio-ecological education for a younger indigenous generation for the sustainable development of the North regions is transformative and managative at the same time. Its resulting parameter is socio-ecological competence.

Let's note the fact that socio-ecological competence as a special model of behaviour is one of the concepts of a new scientific trend - sociology and pedagogical ecology. Combining and integrating cognitive, pragmatic and value-based parameters, it provides overcoming the gap between ecological and social knowledge, skills and experience and their practical application in the system of rules, and norms of behaviour which a younger indigenous generation should follow.

The features of socio-ecological competence characterising it as a separate concept are principles of regulating interactions and behaviour of a young person in the systems "person - society - nature" [3]. Socioecological competence reflects scientifically grounded scope of knowledge, skills and experience, those general requirements for younger generation with the account of theoretical and practical experience.

In general, socio-ecological knowledge is determined by the regularitites of ecology and socialization, personality development. Socio-ecological skills (competences) are understood as the combination of successive actions, based on knowledge of theory and practice of ecological and social content. Mostly these are meta-skills - skills to think ecologically and act socially, analyze facts and events from the ecological and social point of view.

The content of the modules is determined by creating the social and ecological constructs in the minds of younger indigenous generation when studying subject areas. Let us represent fragments of developed and approved modules.

Module 1. Biosphere and its role in the life of the indigenous population.

Biosphere regularities and biodiversity of the Northern nature. Domiant parameters of the Northern environment. Ecology, society as systems and factors of life activity. Socio-ecological competence and tolerance. Aboriginal fishery. Climatic and chemico-technological changes for commercial activities. Ellimination causes and methods. Siberian wildlife parks and their role in the life of indignous people and biodiversity of the life system.

Module 2. Sociocultural sphere and its role in the life of indigenous population.

Social factors and regularities. Number of indigenous Northern people and their role in the life of society. Forecast and perspectives of demographic situations in Northern regions. Health, education and culture as factors of sustainable living of an indignous citizen. Global challenges of culture and health care. Indigenous culture and its preserving. Indigenous activities. Deer breeding, fishing, hide manufacture. Socialization of indigenous people. Polyculture of a younger generation.

Module 3. Ecosphere and its role in life of indigenous people.

Resource components of ecosphere. Renewability and non-renewability of resources. Natural resources as reserves in life activity of indigenous people. Global warming impact on the climate of the North. Resources depletion in the conditions of the region's sustainable development. Younger indigenous generation and ecological crises. Water as a natural resource. Water consumption challenges. Northern land and possibilities of soil resources. Preservation and renovation of the soil. Retrofit, erosive destructions. Oil spills and their impact on indigenous lands.

Module 4. Energy sphere in life activity of the indigenous population.

Natural energy and ways of its utilization. Ways to increase resources production and utilization. Thermal power. Variety of sources based on coal, oil and gas. Pollution and its main causes. Criteria and assessment parameters.

Module 5. Healthy lifestyle of a younger generation as a factor of the sustainable development of indigenous generation.

Health (physical, psychological, emotional, general), risk factors for the younger generation. Living environment and its parameters. Harmful and toxic substances and their influence on the alive systems. LOC of diverse effects (air, water, soil). Health and environmentsl pollution. Attitude to environmental pollution for health maintanance. Nutrition and health of a younger generaion. Emulsifies, coloring agents, alkaloids, as harmful sources for the health of a younger generation.

Harmful addictions (illnesses) of a younger generation. Drug-taking. Alcohol addiction. Nicotine addiction. Sources and ellimination methods.

Module 6. Management of sustainability of a younger indigenous generation.

Management and types of environmental management. Environmental management in the North. Legislation and regulating within the area of indigenous population. Topical importance of the sustainable development of indigenous population in the North. Historical and modern discource of developing parameters for the sustainable development. Legal documents, reflecting sustainable development of the indigenous population. Rationality of the scenario about the development of indigenous population as a northern community.

The process of implementing the model of socioecological education of a younger indigenous generation for the sustainable development of the region (KhMAD - Yugra) is carried out in the system of life-long education and on the bases of laboratories of Ethnic education (Surgut State Pedagogical University). Integrity of socio-ecological education has been provided by the inclusion of content modules into the educational process vertically and horisontally.

Practice-oriented classes in the tune of activitites of indigenous population were of great importance. The classes were on traditions, culture, special technologies based on natural raw materials. Let us note some themes represented in the elective disciplines.

"Birch bark and operation techniques with it"- a practical class about the work of Khants with natural material. 
"Fur clothing and footwear by Wei" - a practical class about creating necessary things by the indigenous population.

"Technological peculiarities of wood works (log canoe)" - a practical class about the work of Mansi with natural material.

"Technology of song creating"- a practical class about the peculiarities of the the song by Nenets Vipinemya - about Amanitaceae mother for keeping a family, tribal lands, deer.

Dealing with integrated concepts (region, surrounding, culture, society, tribe, natural conformity and other), students estimated modern condition and the role of their younger generation in the sustainable development of an indigenous younger generation. Being not indifferent to the issues under study, students joined the scientific work on the themes demanded during the model implementation. Talking about the fields of scientific research, let us note some variants of the themes: "Strategy for the sustainable development of my ethnos", "Studying natural objects for increasing their resistance to technogenic environment", "Health of a younger generation and harmful habits", "Socioecological factors and rational life activity", "Estimating the technogenic and ecological nature of oil and gas processing enterprise for the sustainable development of the region", "Studying the ways to reduce man-caused risks for the northern nature", "Estimating and value of natural areas as specific territories", "Studying local communities for developing civic consciousness with the account of autonomy".

\section{Methods used during the implementation}

Table 1. Indicators and parameters of socio-ecological competence for educating a younger indigenous generation

\begin{tabular}{|c|c|c|}
\hline Indicators & $\begin{array}{l}\text { Subject-matter } \\
\text { and appearance }\end{array}$ & $\begin{array}{l}\text { Parameters of socio- } \\
\text { ecological } \\
\text { competence }\end{array}$ \\
\hline $\begin{array}{l}\text { Subject bases } \\
\text { (humanitarian, } \\
\text { scientific, } \\
\text { trends) }\end{array}$ & $\begin{array}{l}\text { Developing } \\
\text { integrated ideas } \\
\text { about different } \\
\text { spheres of activity } \\
\text { (social, natural, } \\
\text { ecological) on the } \\
\text { synthesis, analysis } \\
\text { of the concepts, } \\
\text { generality, } \\
\text { personal } \\
\text { enrichment }\end{array}$ & $\begin{array}{l}\text { knowledge- } \\
\text { representations, } \\
\text { knowledge-images } \\
\text { (socio-ecological } \\
\text { view) }\end{array}$ \\
\hline Conceptual & $\begin{array}{l}\text { Conceptual } \\
\text { importance of } \\
\text { understanding } \\
\text { social, ecological } \\
\text { problems, cause- } \\
\text { effect analysis }\end{array}$ & $\begin{array}{l}\text { World-view } \\
\text { judgements, } \\
\text { conceptual } \\
\text { importance of the } \\
\text { socio-ecological } \\
\text { thinking }\end{array}$ \\
\hline Integrational & $\begin{array}{lr}\text { Integrting } & \text { facts, } \\
\text { theories } & \text { while } \\
\text { creating } & \text { unified } \\
\text { scientific } & \text { world } \\
\text { view } & \\
\end{array}$ & $\begin{array}{l}\text { Integrated knowledge, } \\
\text { skills, worldview }\end{array}$ \\
\hline Active & $\begin{array}{l}\text { Cognitive, } \\
\text { research, }\end{array}$ & $\begin{array}{l}\text { Metasubject } \\
\text { competences, }\end{array}$ \\
\hline
\end{tabular}

\begin{tabular}{|l|l|l|}
\hline & practical activity & $\begin{array}{l}\text { experience of } \\
\text { practical activity }\end{array}$ \\
\hline
\end{tabular}

The problems stated in the article have been solved with the following methods of research: theoretical (literature review on the topic of research, studying scientific materials and publications); empirical (pedagogical observation, testing, questionaire survey, comparative analysis), mathematical statistics methods.

Model implementation brought the parameters of socio-ecological competence to high levels, which was the most important goal of the research. During the experiment representatives of a younger indigenous generation (Khanty, the Mansis, the Tartars) developed mental skills and abilities "think — act — think — think practicaly".

$12.0 \%$ of students in the experimental group and $38 \%$ of students in the control group had a low level of competence. At the high level there were students of the experimental group with the results $28.0 \%$. The effectiveness of the control group was rather low, only $16.00 \%$. The results at the intermediate level were $3 \%$ higher than in the experimentl group.

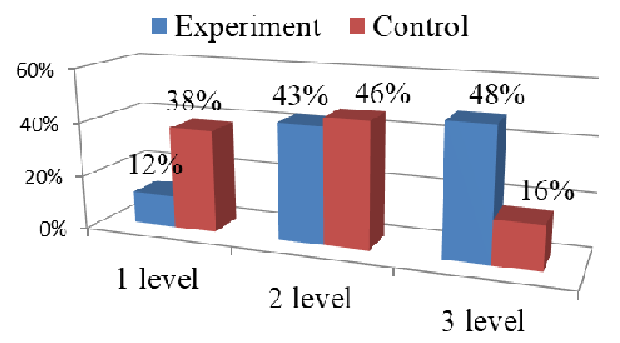

Figure 1. Level expressiveness of socio-ecological competence for students of a younger indigenous generation

Let us note that during the experiment there was a positive dynamics of socio-ecological competence parameters. Along that, there were positive trends in personal development of every student - a representative of the indigenous population. Students expressed their opinions on the following issues: socio-ecological issues reveal contemporary character of problematic areas, study natural and man-made environment; reveal the role and importance of the ethnos in region's activity as a specific oil-gas system; disclose polycultural facts of interethnic cooperation between the Kanty and the Mansis.

Positive responses prove the importance of the model for developing socio-ecological competence of a younger indigenous generation in the region. Besides, the efficiency of the model has been provided and connected with certain types of activity and conditions, they are:

1) choosing an individual development pathway of socio-ecological competence, implementation methodology and technology, educators' professionalism;

2) understanding that sustainable development of the region is a factor and condition of development of the indigineous population; 
3) motivation and interest of the younger indigenous population to the possibility to develop socio-ecological competence not only in theory but in practice;

4) development of socio-ecological competence is built on the principles of face-to-face communication, visualization with traditions and culture of the indigenous population.

\section{Conclusion}

A younger generation of indigenous people of Northern territories lives in conditions which require a high level of socio-ecological competence as an integral personal characteristics, providing a high level of socialization.

The article solves the determined problems. It discloses the pecularities of the social and ecological discourse for the sustainable development of the region. The possibilities of the content modules have been shown for the personal development of younger indigenous people of the Northern territories and their training for life activity in the regional community.

The scientific character of the work is conducted with the methodological model validation, choice of content modules, methods and ways of their implementation.

High practical character of the model is connected with involving younger generation into the activity where natural, cultural, artistic materials are used. It is highly demanded in the life of indiginous population.

\section{References}

1. A.G. Aganbegyan, Bull. of the IE RAS. 1, 7 (2018)

2. O. Bogomolov, The world of transform. 1, 34 (2015)

3. U.V. Bromley Ethnical social processes: theory, history, modernity, 332 (1987)

4. V.I. Bulatov, Analytical review, SPSTL SB RAS, 116 (2012)

5. A.P. Gudyma Social-Philosophical and Ecological Aspects of the Sustainable Development of the Scanty Northern Peoples, 343 (2000)

6. Euro-Asian Integration: problem points and ways of development. Project "Social-political dimension of the processes of Euro-Asian integration", 3 (2017)

7. G.I. Egorova, N.I. Loseva, O.A. Ivanova, B.M. Chabarova, O.M. Demidova, Advan. in Intell. Sys. and Comp., 45 (2019)

8. G.I. Egorova, Devloping noospheric ideas in the pedagogical science and educational practice, (2019)

9. K.Ya. Kondratiev, K.S. Losev, Bulletin of RAS, 72, 505 (2002)

10. Conception of the Sustainable Development of the Scanty Northern Peoples of the KhantyMansiisk autonomous district - Yugra till 2025year, 122 (2020)
11. I.F. Vereshagin, K.S. Zaikov, A.M. Tamitskii, T.I. Troshina, F.KH. Sokolova, N.K. Kharlampieva and others.; edited by N.K. Kharlampieva Ethnical and national processes in the Arctic: tendencies, challenges and perspectives, 325 (2017) 